\title{
AVALIAÇÃO DE RESISTÊNCIA DE CULTIVARES DE AMENDOIM DE HÁBITO DE CRESCIMENTO RASTEIRO A ENNEOTHRIPS FLAVENS MOULTON (THYSANOPTERA: THRIPIDAE)
}

\author{
A.L. Boiça Junior ${ }^{1}$, N.R. Chagas Filho' ${ }^{2}$ I.J. de Godoy ${ }^{3}$, A.L. Lourenção ${ }^{4}$, J.R. de Souza ${ }^{1}$ \\ ${ }^{1}$ Universidade Estadual Paulista, Faculdade de Ciências Agrárias e Veterinárias, Departamento de Fitossani- \\ dade, Laboratório de Resistência de Plantas a Insetos, Via de Acesso Prof. Paulo Donato Castellane, s/no, \\ CEP 14884-900, Jaboticabal, SP, Brasil. E-mail: aboicaj@@fcav.unesp.br
}

RESUMO

\begin{abstract}
Devido a sua ampla distribuição e aos danos acarretados, Enneothrips flavens Moulton destacase como a principal praga do amendoim no Brasil. O objetivo do presente trabalho foi avaliar, em condições de campo, o comportamento de quatro cultivares de amendoim de hábito de crescimento rasteiro sob infestação natural de E. flavens. Os experimentos foram desenvolvidos na área experimental do Departamento de Fitossanidade da FCAV/UNESP - Campus de Jaboticabal, SP. O delineamento experimental utilizado foi em blocos ao acaso, com quatro tratamentos em seis repetições. Foram utilizadas os cultivares IAC Caiapó, IAC 125, IAC 147 e IAC Runner-886. Foram avaliados o número de ninfas e adultos de E. flavens, porcentagem de folíolos atacados, sintomas de intensidade de ataque, número de brotos apicais por planta, massa seca das plantas, produção de grãos em casca $\left(\mathrm{kg} \mathrm{ha}^{-1}\right)$ e a massa seca de 100 sementes $(\mathrm{g})$. Os cultivares não diferiram quanto ao nível de infestação de ninfas e adultos de E. flavens. O período de maior infestação de ninfas ocorreu entre 15 e 41 DAE, e de adultos entre 15 e 48 DAE. Analisando-se a produção, o cultivar IAC Caiapó comportou-se como portador de resistência do tipo tolerância ao ataque de E. flavens.
\end{abstract}

PALAVRAS-CHAVE: Tripes, Arachis hypogaea, resistência de plantas a insetos.

\section{ABSTRACT}

EVALUATIONOFPEANUTCULTIVARSWITHRUNNERGROWINGHABITFORRESISTANCE TOENNEOTHRIPS FLAVENS, MOULTON(THYSANOPTERA:THRIPIDAE). Due toits widespread distribution and known damages, Enneothrips flavens Moulton is considered the major pest of the peanut crop in Brazil. The objective of the present study was to evaluate the behavior of four runner peanut cultivars under natural field infestation of this insect. The experiments were carried out in the experimental area of FCAV/UNESP, Jaboticabal, state of São Paulo, Brazil, using a completely randomized block design with 4 treatments and 6 replications. The cultivars studied were IAC Caiapó, IAC 125, IAC 147 and Runner IAC 886. Insect infestation and damage, as well as plant behavior were evaluated as to the number of nymphae and adults, percentage of attacked leaflets, symptoms of attack intensity, number of apical buds/plant, plant dry weight, yield of unshelled pods/plant and 100 kernel weight. No significant difference was noted between cultivars regarding the level of $E$. flavens (adult and nymphae) infestation. The largest nymphae infestation was recorded at the 15-41 DAE (days after emergency) period. As for the adults, the largest infestation occurred between 15 and 48 days after emergence. The evaluation of yield performance under thrips (E. flavens) infestation suggested that the cultivar IAC Caiapó behaved as tolerant to the attack of this insect.

KEY WORDS: Thrips, Arachis hypogaea, host plant resistance.

\section{INTRODUÇÃO}

No Brasil, na safra 2009/2010, foram produzidas 233,9 mil toneladas de amendoim (Arachis hypogaea L.) em uma área de aproximadamente 92,4 mil hectares. O Estado de São Paulo destaca-se como o maior produtor, atendendo a demanda brasileira com cerca de 189,6 mil toneladas em uma área plantada de, aproximadamente, 67,8 mil hectares (CONPANHIA..., 2010).

2Syngenta, Lucas do Rio Verde, MT, Brasil.

${ }^{3}$ Instituto Agronômico, Centro de Fitossanidade, Campinas, SP, Brasil.

${ }^{4}$ Instituto Agronômico, Centro de Grãos e Fibras, Campinas, SP, Brasil. 
A cultura do amendoim, normalmente, é afetada por várias pragas e, dentre estas, o tripes-do-prateamento Enneothrips flavens Moulton (Thysanoptera: Thripidae) destaca-se como principal praga, no Brasil. Os adultos desse tripes medem cerca de 2 $\mathrm{mm}$ de comprimento. As formas jovens apresentam coloração amarelada sem asas, enquanto os adultos são escuros e possuem asas franjadas. Esses insetos ficam abrigados em folíolos fechados onde perfuram o tecido para sugar o conteúdo que extravasa das células causando danos que vão desde ferimentos até abscisão dos folíolos (GALlo et al., 2002).

Os danos às plantas ficam visíveis após a abertura dos brotos, quando as folhas mostram deformações nítidas, encarquilhamento e prateamento. Esses danos dificultam a absorção de energia luminosa pela planta, levando à diminuição da atividade fotossintética com consequente redução no desenvolvimento das plantas, diminuindo dessa forma a produção (AlmeidA; ARRUdA, 1962).

O método de controle mais utilizado tem sido o químico, por meio da utilização deinseticidas, através dos quais a praga é controlada com três a seis pulverizações duranteo ciclo da cultura (LASCA,1986). Outros métodos decontrole podem serempregados, taiscomo a utilização de cultivares resistentes. De acordo com LARA (1991), este método é considerado ideal, uma vez que as populações das pragas podem ser mantidas abaixo do nível de dano econômico, reduzindo distúrbios ambientais e sem exigir conhecimentos específicos do agricultor, nem custos adicionais.

Godoy et al. (1999) relataram que a resistência de cultivares de amendoim ao tripes tem sido pouco explorada no Brasil, pois poucos pesquisadores tem se dedicado ao seu estudo. De acordo com os mesmos autores, a utilização de cultivares com resistência a E. flavens poderia representar ganhos adicionais em produtividade, pois promoveredução significativa no custo de produção pela redução do controle químico.

Existem poucas informações a respeito da resistência de plantas de amendoim a E. flavens no Brasil. Pesquisas mostram que os cultivares IAC Tupã, IAC Poitara, IAC Oirã e Tatu, de hábito de crescimento ereto, são suscetíveis a E. flavens, enquanto IAC Caiapó, IAC Gigante e IAC Jumbo são resistentes (CAMPOS et al., 1998). GABRIEL et al. (1996) verificaram que o cultivar Tatu é mais infestado por E. flavens que os cultivares IAC Caiapó e IAC Jumbo. Moraeset al. (2005), em estudos sobre a influência do ataque de $E$. flavens na produtividade dos cultivares IAC Tatu ST, IAC 5, IAC 22, IAC Runner-886, IAC Caiapó e Tégua, relataram que o cultivar IAC Caiapó demonstrou possuir resistência a $E$. flavens.

Dessa forma, o objetivo deste trabalho foi avaliar o comportamento de quatrocultivares de amendoim, com hábito de crescimento rasteiro, sob infestação natural de E. flavens em condições de campo.

\section{MATERIAL E MÉTODOS}

Oexperimento foi conduzido na área experimental do Departamento de Fitossanidade da FCAV/ UNESP, Jaboticabal, SP, no ano agrícola 2006/2007. Olocal dos experimentos foi preparado pelo sistema convencional, com uma aração e duas gradagens. $\mathrm{Na}$ adubação, foram empregados $350 \mathrm{~kg}$ de adubo por hectare, da fórmula 4-30-10, aplicados no sulco da semeadura (RAIJ, 1997).

O delineamento experimental foi em blocos ao acaso, com quatro tratamentos em seis repetições. Cada unidadeexperimental constituiu de cincolinhas de $5 \mathrm{~m}$ de comprimento, espaçadas $0,9 \mathrm{~m}$ entre si. As três linhas centrais foram consideradas como área útil $\left(10,80 \mathrm{~m}^{2}\right)$, sendo duas delas utilizadas para as avaliações da infestação do tripes, contagem do número de brotos apicais e massa seca das plantas e uma linha para avaliação da produção do amendoim em casca.

Foram utilizadas os cultivares IAC Caiapó, IAC 125, IAC 147 e IAC Runner-886. Sete dias após a semeadura, foi realizado o desbaste, deixando-se de 12 a 13 plantas por metro linear. Antes da semeadura, as sementes foram tratadas com thiram, fungicida de contato, na dose $144 \mathrm{~g}$ i.a por $100 \mathrm{~kg}$ de semente. Após a germinação, sempre que necessário, as doenças foliares foram controladas em todas as parcelas, mediante pulverizações com difenoconazole, na dose de $0,35 \mathrm{~L} \mathrm{ha}^{-1}$. O controle das plantas daninhas foi feito com a aplicação de trifluralina na dose 801 g i.a.ha ${ }^{-1}$, em pré-plantio incorporado e, em complementação, sempre que necessário, foram realizadas capinas manuais.

A resistência dos cultivares de amendoim foi avaliada em condições de infestação natural através da contagem do número de ninfas e adultos de $E$. flavens, porcentagem de folíolos infestados, sintomas de intensidade de ataque, número de brotos apicais por planta e massa seca das plantas. A contagem de ninfas e adultos de E. flavens foi realizada semanalmente, iniciando-se aos 15 dias após a emergência (DAE) das plantas e estendendo-se até 100 DAE. Para cada avaliação, foram coletadas ao acaso dez folhas do ápice das plantas por parcela. Estas foram acondicionadas em sacos de papel que foram devidamente identificados para serem mantidos em câmara fria. Posteriormente, foram colocados em placa de Petri onde foi separado, dentre os quatro folíolos presentes na folha apical, o mais desenvolvido. Para isso, utilizou-se uma pinça e um estereoscópico.

Os sintomas de intensidade de infestação causados por E. flavens nos folíolos das plantas de amendoim foram mensurados segundo a escala de notas de Moraes (2005) (Tabela 1). 
Tabela 1 - Escala visual de notas para avaliação de sintomas de infestação causados por Enneothrips flavens em plantas de amendoim.

\begin{tabular}{cl}
\hline Nota & Descrição \\
\hline 1 & Folíolo com ausência de sintomas \\
2 & Folíolo com poucas pontuaç̃̃es prateadas, sem deformações \\
3 & Folíolo com poucas pontuações prateadas, com início de enrolamento das bordas \\
4 & Folíolo com pontuações prateadas generalizadas, com enrolamento das bordas \\
5 & Folíolo com pontuações prateadas generalizadas, com encarquilhamento total \\
\hline
\end{tabular}

Estas avaliações foram realizadas em dez folíolos semiabertos, coletados do terço superior das plantas em cada parcela. Em seguida, eles foram acondicionados em sacos de papel devidamente identificados.

O número de brotos por planta foi determinado por meio da coleta de cinco plantas por parcela aos 22, 40 e 70 DAE. Em seguida, essas plantas foram acondicionadas em estufa de secagem a temperatura 65 a $70^{\circ} \mathrm{C}$ por 72 horas, para determinação da massa seca.

Por ocasião da colheita, foram avaliadas a produção do amendoim em casca $\left(\mathrm{kg} \mathrm{ha}^{-1}\right)$ e a massa seca de 10 sementes $(\mathrm{g})$. A produção foi obtida a partir da coleta manual das vagens em cada uma das três linhas centrais de cada parcela. A massa seca foi obtida através da pesagem de 100 sementes após secagem em estufa a 65 a $70^{\circ} \mathrm{C}$ por 72 horas.

Os dados obtidos foram submetidos à análise de variância pelo teste $\mathrm{F}$ e as médias comparadas pelo teste de Tukey a $5 \%$ de probabilidade.

\section{RESULTADOS E DISCUSSÃO}

Com relação ao número de ninfas de E. flavens, observou-se nas épocas de avaliações que não houve diferença entre os cultivares avaliados, com exceção da quinta avaliação, que foi realizada aos 41 dias DAE, com o cultivar IAC Runner-886 apresentando menor número de ninfas e diferindo dos demais cultivares (Tabela 2). Quanto ao número de adultos nas avaliações realizadas aos 41 e 48 DAE, o cultivar IAC Runner-886 destacou-se, pois apresentou menor infestação de adultos de E. flavens quando comparado com os demais cultivares (Tabela 2).

Como se pode observar, a maior população de $E$. flavens ocorreu dos 15 aos $54 \mathrm{DAE}$ e que aos $15 \mathrm{DAE}$ houve aumento no número de ninfas de $E$. flavens por folíolo (Tabela 2). Este fato possivelmente está associado devidoà área experimental estar localizada em região produtora de amendoim e, portanto, com maior quantidade de plantas hospedeiras, favorecendo a infestação no ensaio, desde o início do seu desenvolvimento. Para Chagas Filho et al. (2008), o período de maior infestação de E. flavens ocorre entre 15 a 41 DAE e a época de maior ocorrência de E. flavens pode variar de acordo com a região e a influência de fatores bióticos e abióticos.

Aos $48 \mathrm{DAE}$, pode-se verificar diminuição do número de ninfas de $E$. flavens por folíolo até o final das avaliações aos 88 DAE. Moraes et al. (2005) relataram que as maiores infestações ocorrem quando há maior emissão de folíolos, havendo decréscimo de E. flavens quando as plantas cessam a emissão de brotações.

A porcentagem de folíolos com a presença de $E$. flavens observadas nas datas de avaliações não apresentou diferenças entre os cultivares, evidenciando que os cultivares foram igualmente infestados por $E$. flavens (Tabela 3). Em relação às notas dos sintomas visuais de danos observados nos folíolos infestados por E. flavens, os resultados indicaram diferenças somente aos 41 e 88 DAE. Nessas épocas de avaliações, o cultivar IAC 125 demonstrou ser o menos atacado quando comparado com os demais cultivares.

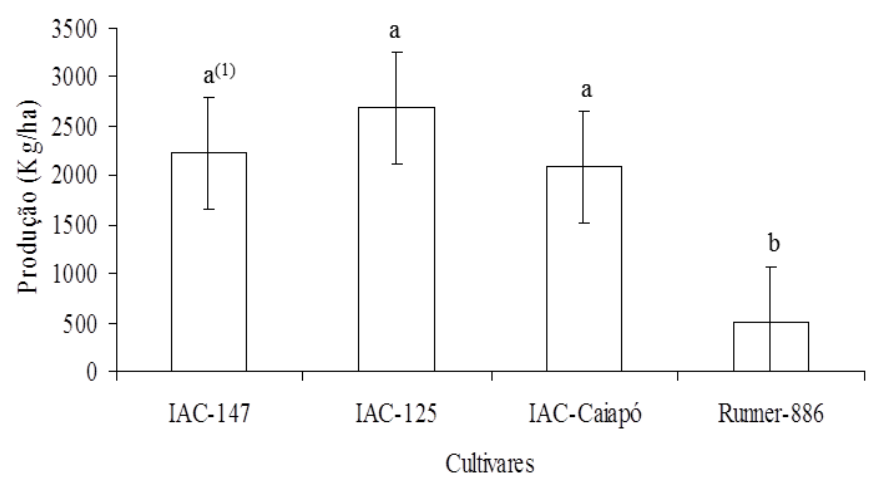

Fig. 1 - Produção de amendoim em casca $\left(\mathrm{kg} \mathrm{ha}^{-1}\right)$ obtida em quatro cultivares de amendoim com hábito de crescimento rasteiro, em condições de infestação natural de Enneothrips flavens em campo. Jaboticabal, SP, 2006/2007.

${ }^{1}$ médias com a mesma letra não diferem entre si, pelo teste de Tukey, a 5\% de probabilidade. 

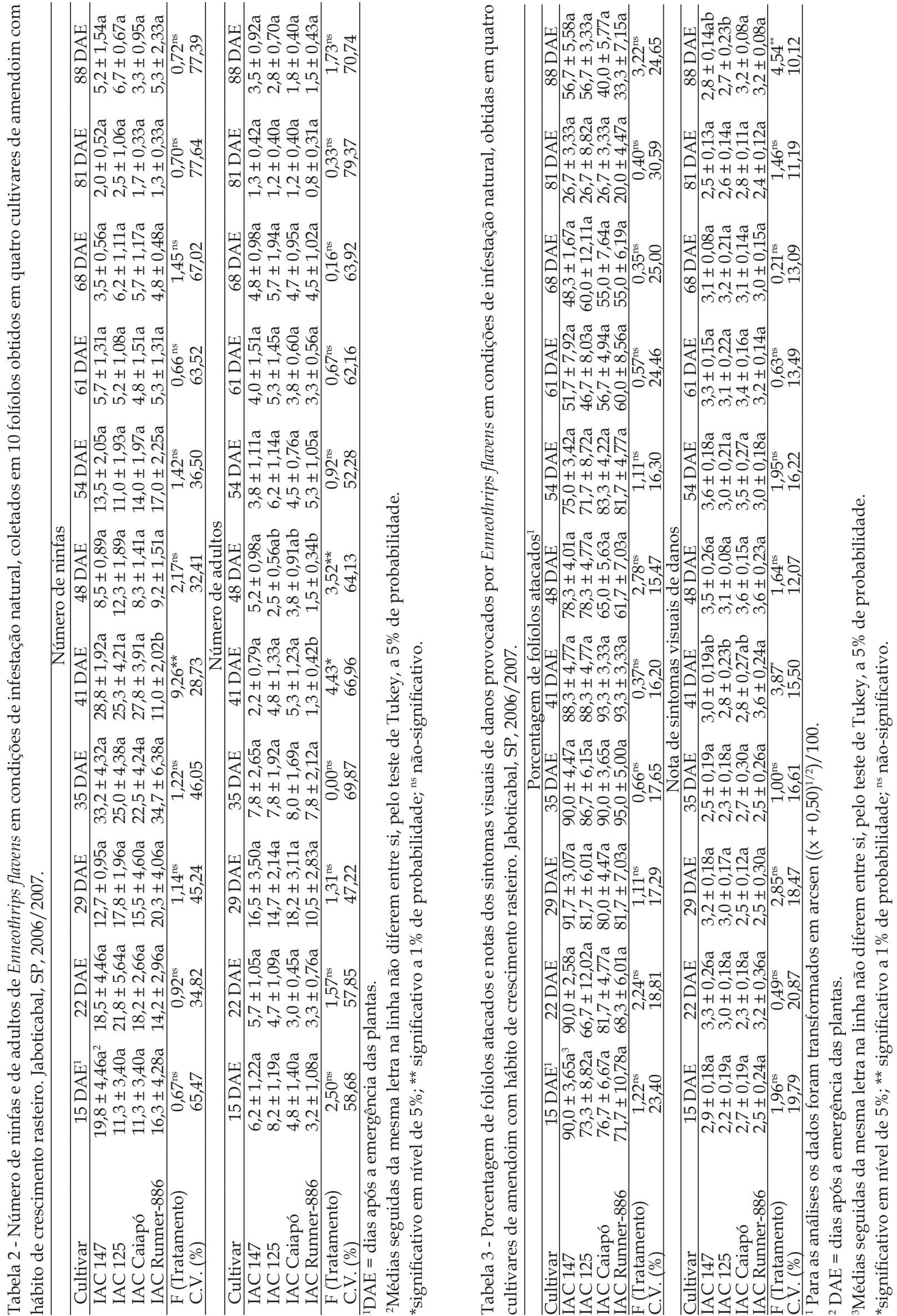
Tabela 4 - Número de brotos por planta e massa seca (g) em cinco plantas, obtidos em quatro cultivares de amendoim com hábito de crescimento rasteiro, em condições de infestação natural de Enneothrips flavens em campo. Jaboticabal, SP, 2006/07.

\begin{tabular}{lcccccc}
\hline \multirow{2}{*}{ Cultivar } & \multicolumn{2}{c}{ Número de brotos por planta } & \multicolumn{3}{c}{ Massa seca $(\mathrm{g})$} \\
\cline { 2 - 6 } & $13 \mathrm{DAE}^{1}$ & 36 DAE & 57 DAE & 13 DAE & \multicolumn{1}{c}{ 36 DAE } & 57 DAE \\
\hline IAC 147 & $11,7 \pm 1,23 \mathrm{a}^{2}$ & $15,7 \pm 3,32 \mathrm{a}$ & $5,8 \pm 0,77 \mathrm{a}$ & $18,2 \pm 3,03 \mathrm{a}$ & $80,8 \pm 13,13 \mathrm{a}$ & $120,0 \pm 11,40 \mathrm{a}$ \\
IAC 125 & $11,5 \pm 0,74 \mathrm{a}$ & $23,6 \pm 3,99 \mathrm{a}$ & $6,1 \pm 1,46 \mathrm{a}$ & $20,6 \pm 3,48 \mathrm{a}$ & $90,0 \pm 10,88 \mathrm{a}$ & $136,7 \pm 9,63 \mathrm{a}$ \\
IAC Caiapó & $12,7 \pm 0,96 \mathrm{a}$ & $19,7 \pm 4,52 \mathrm{a}$ & $6,9 \pm 0,53 \mathrm{a}$ & $17,5 \pm 2,03 \mathrm{a}$ & $102,5 \pm 12,57 \mathrm{a}$ & $130,0 \pm 7,30 \mathrm{a}$ \\
IAC Runner-886 & $13,6 \pm 1,56 \mathrm{a}$ & $15,9 \pm 3,02 \mathrm{a}$ & $3,8 \pm 0,96 \mathrm{a}$ & $19,1 \pm 1,24 \mathrm{a}$ & $95,0 \pm 6,19 \mathrm{a}$ & $125,8 \pm 7,57 \mathrm{a}$ \\
\hline F (Tratamento) & $1,08^{\text {ns }}$ & $1,04^{\text {ns }}$ & $2,61^{\text {ns }}$ & $0,80^{\text {ns }}$ & $0,54^{\text {ns }}$ & $1,04^{\text {ns }}$ \\
C.V. (\%) & 18,94 & 48,14 & 34,86 & 21,18 & 32,77 & 17,36 \\
\hline
\end{tabular}

${ }^{1} \mathrm{DAE}=$ dias após a emergência das plantas.

${ }^{2}$ médias seguidas da mesma letra na coluna não diferem entre si, pelo teste de Tukey, a $5 \%$ de probabilidade.

ns $=$ não-significativo.

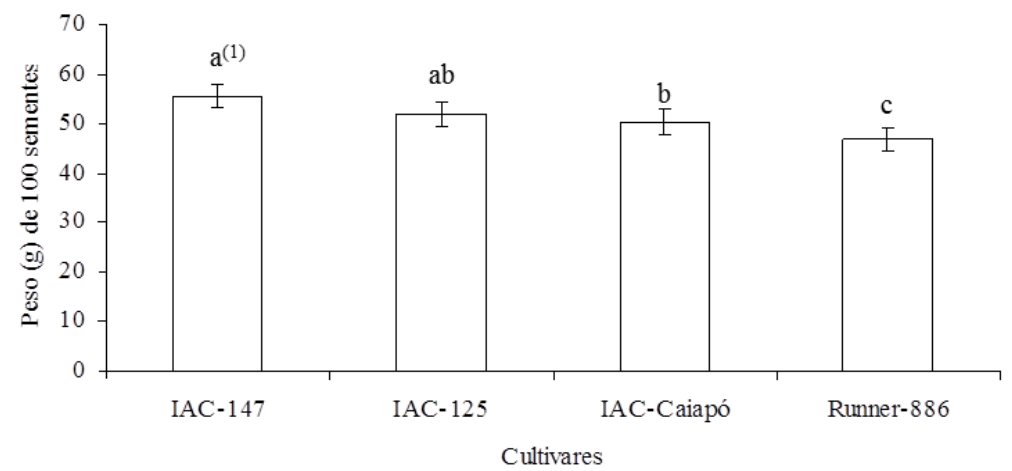

Fig. 2 - Massa de 100 sementes de amendoim (g), obtida em quatro cultivares de amendoim com hábito de crescimento rasteiro em condições de infestação natural de Enneothrips flavens em campo. Jaboticabal, SP, 2006/2007.

${ }^{(1)}$ médias com a mesma letra não diferem entre si, pelo teste de Tukey, a 5\% de probabilidade.

De modo geral, as notas dos sintomas visuais de infestação causadas por E. flavens foram semelhantes entre os cultivares, pois, de acordo com as notas atribuídas (Tabela 1) e os resultados presentes na Tabela 3, que variaram entre 2 e3, observou-se a presença de folíolos com poucas pontuações prateadas, mas sem deformações e folíolos com poucas pontuações prateadas, com início de enrolamento das bordas nas cultivares estudadas.

Considerando-se o número de brotos por planta e a massa seca das plantas (Tabela 4), verificou-se que não houve diferenças entre os cultivares. Pode-se ressaltar que a emissão de brotos por planta foi maior nas duas primeiras avaliações realizadas aos 13 e 36 DAE, sendo que na terceira avaliação, realizada aos 57 DAE, notou-se declínio na emissão de brotos por planta nos cultivares avaliados. Este fato pode ser atribuído às diferenças na arquitetura vegetativa dos cultivares.

No fim do ciclo da cultura, a produção $\left(\mathrm{kg} \cdot \mathrm{ha}^{-1}\right)$ de amendoim em casca mostrou diferenças entre os cultivares avaliados (Fig. 1). Nesse sentido, pode-se inferir que os cultivares IAC 125, IAC 147 e IAC Caiapó foram mais produtivos, apresentando valores superiores a $2.000 \mathrm{~kg} \mathrm{ha}^{-1}$, quando comparados com o cultivar IAC Runner-886 que apresentou valor inferior a $510 \mathrm{~kg} \mathrm{ha}^{-1}$. Entretanto, em função do ciclo do cultivar IAC Caiapó ser mais longo e, dessa forma, sujeito ao ataque de E. flavens por um período maior quando comparado com os outros cultivares, ele consegue suportar o ataque da praga, de modo a apresentar menor redução na produtividade, indicando possuir resistência do tipo tolerância. De acordo com CAMPos (2001), as diferenças entre diferentes cultivares de amendoim em relação à produção de grãos estão relacionadas ao nível de resistência e ao potencial genético de cada genótipo.

Dessa forma, dependendo do cultivar analisado, as reduções na produção podem ser maiores ou menores, sugerindo que a escolha de um cultivar com resistência do tipo tolerância a E. flavens pode ser um importante fator a ser considerado no manejo integrado de pragas na cultura do amendoim.

Considerando a massa seca de 100 sementes (Fig. 2) constatou-se que o cultivar IAC 147 diferiu do cultivar IAC Runner-886, pois apresentou massa de 100 sementes superior a $50 \mathrm{~g}$, ficando os demais cultivares em posição intermediária. 


\section{CONCLUSÕES}

a) Todas os cultivares foram suscetíveis ao ataque de E. flavens, quando submetidos à alta população de ninfas e adultos de E. flavens;

b) O período de maior infestação de ninfas de $E$. flavens ocorreu entre 15 e 41 DAE, e de adultos entre 15 e 48 DAE;

c) O cultivar IAC Caiapó comportou-se como portador de resistência do tipo tolerância ao ataque de E. flavens.

\section{AGRADECIMENTOS}

Ao CNPq pela concessão da bolsa de produtividade em pesquisa ao primeiro e quarto autores $\mathrm{e}$ pela bolsa de doutorado ao segundo autor; à FAPESP pela concessão do auxílio à pesquisa e à Dra. Renata C. Monteiro, ESALQ/USP, pela identificação da espécie de tripes.

\section{REFERÊNCIAS}

ALMEIDA, P.R.; ARRUDA, H.V. Controle de tripes causador do prateamento das folhas do amendoim por meio de inseticidas. Bragantia, v.21, n.38, p.679-687, 1962.

CAMPOS, A.R. Tripes do prateamento Enneothrips flavens Moulton, 1941 (Thysanoptera: Thripidae) em amendoinzeiro: resistência de genótipos, avaliação de danos, integração de genótipos e inseticida e período de proteção ao ataque dos tripes e seus reflexos na produção. 2001. 133f. Tese (Livre Docente) - Faculdade de Engenharia do Campus de Ilha Solteira/ Universidade Estasual Paulista, Ilha Solteira. 2001.

CAMPOS, A.R.; LARA, F.M.; LAZARINI, E.; JOLVINO, A.L; SOUZA, R.S. Resistência de genótipos de amendoim (Arachis hypogaea L.) ao tripes do prateamento Enneothrips flavens Moulton, 1941 (Thysanoptera: Thripidae) na região de Ilha Solteira. In. CONGRESSO BRASILEIRO DE ENTOMOLOGIA, 17., 1998, Rio de Janeiro. Resumos. Rio de Janeiro: SEB, 1998. p.638.

CHAGAS FILHO, N.R.; BOIÇA JUNIOR, A.L.; GODOY, I.J.; LOURENÇÃO, A.L.; RIBEIRO, Z.A. Resistência de cultivares de amendoim de hábito de crescimento ereto a Enneothrips flavens Moulton (Thysanoptera: Thripidae). Arquivos do Instituto Biológico, São Paulo, v.75, n.2, p.149156, 2008.

COMPANHIA NACIONAL DE ABASTECIMENTO. (Brasil). Acompanhamento de Safra Brasileira: grãos. Brasília: CONAB, 2010. 42p. (Publicação mensal).

GABRIEL, D.; NOVO, J.P.S.; GODOY, I.J.; BARBOZA, J.P. Flutuação populacional de Enneothrips flavens Moulton em cultivares de amendoim. Bragantia, v.55, n.2, p.253-257, 1996.

GALLO, D.; NAKANO, O.; SILVEIRA NETO, S.; CARVALHO, R.P.L.; BATISTA, G.C.; BERTI FILHO, E.; PARRA, J.R.P.; ALVES, S.B.; VENDRAMIM, J.D.; MARCHINI, L.C.; LOPES, J.R.S.; OMOTO, C. Entomologia agrícola. Piracicaba: FEALQ, 2002. 920p.

GODOY, I.J.; MORAES, S.A.; ZANOTTO, M.; SANTOS, R.C. Melhoramento do Amendoim. In: BORÉM A. (Ed.). Melhoramento de espécies cultivadas. Viçosa: Universidade Federal de Viçosa, 1999. v.1, p.51-94.

LARA, F.M. Princípios de resistência de plantas a insetos. São Paulo: Ícone, 1991. 336p.

LASCA, D.H.C. Amendoim (Arachis hypogaea). Campinas: CATI, 1986. p. 64-80. (Manual CATI, n. 8).

MORAES, A.R.A. Efeito da infestação de Enneothrips flavens Moulton no desenvolvimento e produtividade de seis cultivares de amendoim, em condição de campo. 2005. $104 \mathrm{f}$. Dissertação (Mestrado em Tecnologia da Produção Agrícola) - Instituto Agronômico de Campinas, Campinas, 2005.

MORAES, A.R.A.; LOURENÇÃO, A.L.; GODOY, I.J.; TEIXEIRA, G.C. Infestation by Enneothrips flavens Moulton and yield of peanut cultivars. Scientia Agricola, v.62, n.5, p.469-472, 2005.

RAIJ, B.; CANTARELLA, H.; QUAGGIO, J.A.; FURLANI, A.M.C. Recomendações de adubação e calagem para o estado de São Paulo. Campinas: Instituto Agronômico Fundação IAC, 1997. 285p. (Boletim Técnico 100).

Recebido em 24/11/10

Aceito em 2/2/12 